\title{
RELIABILITY EVALUATION OF THE CITY TRANSPORT BUSES UNDER ACTUAL CONDITIONS
}

\author{
Joanna Rymarz ${ }^{1}$, Andrzej Niewczas ${ }^{2}$, Jozef Stoklosa ${ }^{3}$ \\ ${ }^{1}$ Lublin University of Technology, Lublin, Poland \\ Ph.: 81538 4259, e-mail: j.rymarz@pollub.pl \\ ${ }^{2}$ Motor Transport Instytut, Warsaw, Poland \\ Ph.: 513023 906,e-mail: niewczas-andrzej@wp.pl \\ ${ }^{3}$ University of Economics and Innovations in Lublin, Lublin, Poland \\ Ph.: +48 8174932 43, e-mail: jozef.stoklosa@wsei.lublin.pl
}

\begin{abstract}
The purpose of this paper was to present a reliability comparison of two types of city transport buses. Case study on the example of the well-known brands of city buses: Solaris Urbino 12 and Mercedes-Benz 628 Conecto L used at Municipal Transport Company in Lublin was presented in details. A reliability index for the most failure parts and complex systems for the period of time failures was determined. The analysis covered damages of the following systems: engine, electrical system, pneumatic system, brake system, driving system, central heating and air-conditioning and doors. Reliability was analyzed based on Weibull model. It has been demonstrated, that during the operation significant reliability differences occur between the buses produced nowadays.
\end{abstract}

Keywords: reliability, Weibull model, city transport buses

\section{Introduction}

In municipal transport companies, vehicles reliability is a crucial parameter in the maintenance practice. Choosing the right type of the vehicle, which is adapted to specific operating conditions is very difficult. Currently, on the Polish market a large number of low-floor vehicles of diverse lengths and capacity, and with the accessories adapted to the needs of a particular transport company is offered. Literature shows that a lot of attention is paid to the problem of vehicles reliability. Many authors are professionally engaged in reliability modelling and defects analysis in the tested vehicles, including a.o.th. (Naikan and Kapur, 2006; Chukova, Attardi 2005; Arnold R. et al., 2004; Aksezer, 2011; Kleynera and Sandborn, 2005; or Gong, 2006).

Reliability is also an important parameter, used to evaluate the quality of the municipal transport companies. If there is a possibility to determine the type and the failure number of vehicles, as well as an estimation of the mileage between those failures, fleet readiness problems could be minimized or even eliminated (Majeske, 2007; Murthy et al., 2002; Pecht, 2006; Rymarz et al., 2013; Shafiee et al., 2013). The introduction of new types of vehicles entails knowledge of the operating characteristics of these vehicles. This is necessary not only to assess the suitability of different types of vehicles and determine their operating costs, but also to determine the type and number of components or the appropriate density of maintenance personnel (Grądzki et al., 2015).

Monitoring of operational suitability of vehicles and their main components, especially with separation of "weak points" (Gołąbek, 1993) are basis for rationalization of the technical services range, according to criterion of not exceeding acceptable levels of damage risk.

Selection of the reliability analysis method depends on the type of the analyzed technical object and the required accuracy of the estimate. The method should take into account all of the possible factors affecting the reliability of the analyzed system, and at the same time the simplest procedure for registration and calculation as possible (Matuszak, 2010).

\section{Studies process}

The study included 22 buses of Mercedes-Benz 628 Conecto LF and 20 buses of Solaris Urbino 12. All buses were observed from the first day of the operation (January 2009 for Mercedes-Benz and June 2008 for Solaris) to the 48 and 54 months for Mercedes and Solaris buses, respectively. The studies were conducted under natural conditions. 
The analysis covered damages of the following systems: engine (US) (including engine, cooling and supply system), electrical system (UE), pneumatic system (UP), brake system (UH), driving system (UN) (including suspension and steering gear), central heating and air-conditioning (UOK) and doors (UD). Damages were recorded in the range of vehicle mileage failures occurrence. Reliability was analyzed based on Weibull model (Kleynera et al., 2005).

\section{Study results}

Figures 1 and 2 present frame charts of the failure-free operation of the selected structural systems, for Mercedes and Solaris buses, respectively. Median of the mileage between damages of the analyzed systems of both types of buses was calculated. Average mileage between damages for Mercedes buses for the central heating and air-conditioning, and doors was about 100 thousand $\mathrm{km}$, for electrical system, engine and driving system was about 50 thousand $\mathrm{km}$ and for the pneumatic and brake system above 165 thousand $\mathrm{km}$. In case of Solaris buses median mileage between damages was higher than for the Mercedes buses, and amounts respectively 165 thousand $\mathrm{km}$ for the driving system, 214 thousand $\mathrm{km}$ for the braking system, 110 thousand $\mathrm{km}$ for the brake system, 196 thousand $\mathrm{km}$ for the doors and 245 thousand $\mathrm{km}$ for heating and air-conditioning.

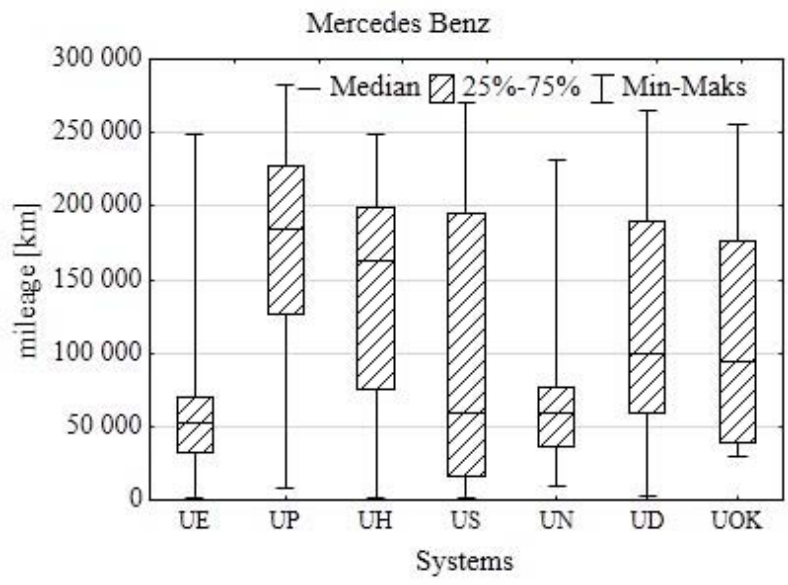

Figure 1. Box plots presenting failures occurrence of the selected Mercedes Benz buses systems: engine (US), electrical system (UE), pneumatic system (UP), brake system (UH), driving system (UN), central heating and air-conditioning (UOK) and doors (UD)

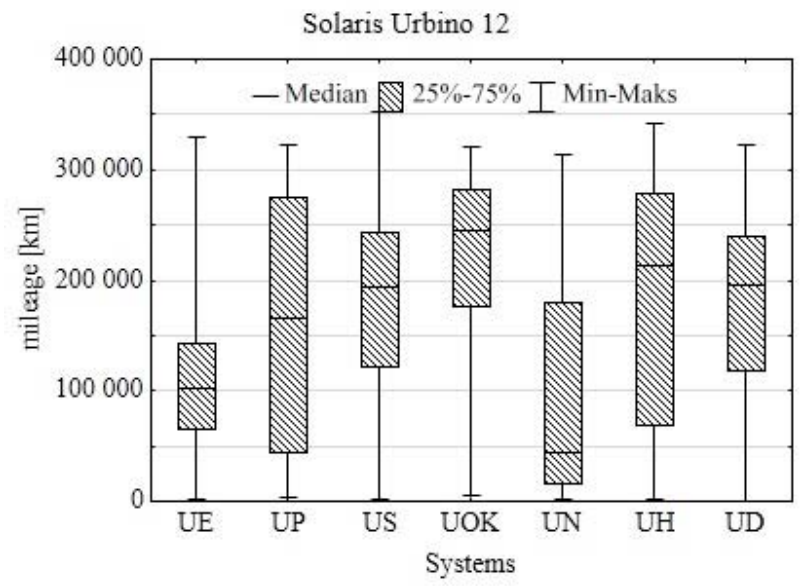

Figure 2. Box plots presenting failures occurrence of the selected Solaris Urbino buses systems: engine (US), electrical system (UE), pneumatic system (UP), brake system (UH), driving system (UN), central heating and air-conditioning (UOK) and doors (UD) 


\section{Reliability function analysis}

In reliability evaluation a Weibull model was used. A parameter estimation of a two-parameter Weibull distribution was performed by a maximum likelihood method (Table 1) (Chukova et al., 2004; Kaplan, Meier, 1958). A shape parameter is equal to slope coefficient of the fitted regression line, whereas the scale parameter can be calculated as the quotient (intercept/slope). Nonparametric methods of this type are used a.m. in assessment of the expected warranty time of vehicles (Gong, 2006).

Different shape parameter values indicate a diversity of reliability distribution. In case of engine and doors for Mercedes buses and brake, driving and pneumatic systems for Solaris buses, the shape parameter value was below one, and it can be interpreted as a result of after production damages. In case of brake and pneumatic systems for Mercedes buses, the shape parameter value was close to unity. It indicates predominance of it means that there is a domination of misfortune damages. In case of driving system, where $\mathrm{c}=1.3981$ and electrical systems $\mathrm{c}=1.4043$ or central heating and air-conditioning $\mathrm{c}=1.4208$ for Mercedes buses, and electrical system where $c=1.6406$ for Solaris buses, the shape parameter value was above one. It means that systems damages are a deciding factor for determined by operational wear of parts.

Table 1. Scale and shape parameters of a two-parameter Weibull distribution according to types of buses and their systems

\begin{tabular}{|c|c|c|c|}
\hline Bus type & Structural systems & Shape parameter [c] & Scale parameter [b] \\
\hline Mercedes Benz & \multirow{2}{*}{ all systems } & 1.1312 & 100800 \\
\hline Solaris Urbino 12 & & 1.3057 & 171200 \\
\hline Mercedes Benz & \multirow{2}{*}{ engine (US) } & 0.81404 & 98912 \\
\hline Solaris Urbino 12 & & 1.2770 & 217600 \\
\hline Mercedes Benz & \multirow{2}{*}{ brake system (UH) } & 1.1844 & 182400 \\
\hline Solaris Urbino 12 & & 0.84815 & 211100 \\
\hline Mercedes Benz & \multirow{2}{*}{ driving system (UN) } & 1.3981 & 88642 \\
\hline Solaris Urbino 12 & & 0.81336 & 89965 \\
\hline Mercedes Benz & \multirow{2}{*}{ electrical system (UE) } & 1.4043 & 67541 \\
\hline Solaris Urbino 12 & & 1.6406 & 127600 \\
\hline Mercedes Benz & \multirow{2}{*}{ pneumatic system (UP) } & 1.1877 & 203900 \\
\hline Solaris Urbino 12 & & 0.87703 & 179100 \\
\hline Mercedes Benz & \multirow{2}{*}{ central heating and air-conditioning (UOK) } & 1.4208 & 122100 \\
\hline Solaris Urbino 12 & & 1.1767 & 290100 \\
\hline Mercedes Benz & \multirow{2}{*}{ doors (UD) } & 0.96552 & 134500 \\
\hline Solaris Urbino 12 & & 1.3422 & 222000 \\
\hline
\end{tabular}

The scale parameter (characteristic ability) indicates how long (mileage) $63.2 \%$ of the observed buses break down. For the pneumatic and brake system in both types of buses, more than $63 \%$ of buses have failed at mileage about 200 thousand $\mathrm{km}$. For the driving system this was half of the value -90 thousand $\mathrm{km}$. In turn of the systems: central heating and air-conditioning, doors and engine $63.2 \%$ of the analyzed Solaris busses have more than two times longer mileage failsafe comparing to the Mercedes buses.

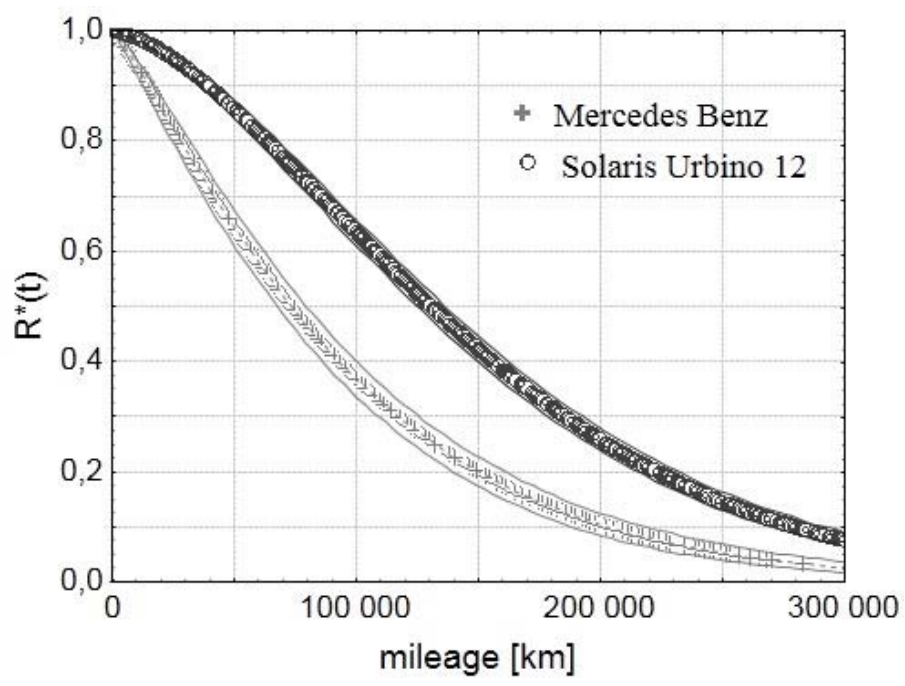

Figure 3. Reliability function diagram of all studied systems of Solaris Urbino and Mercedes Benz buses 


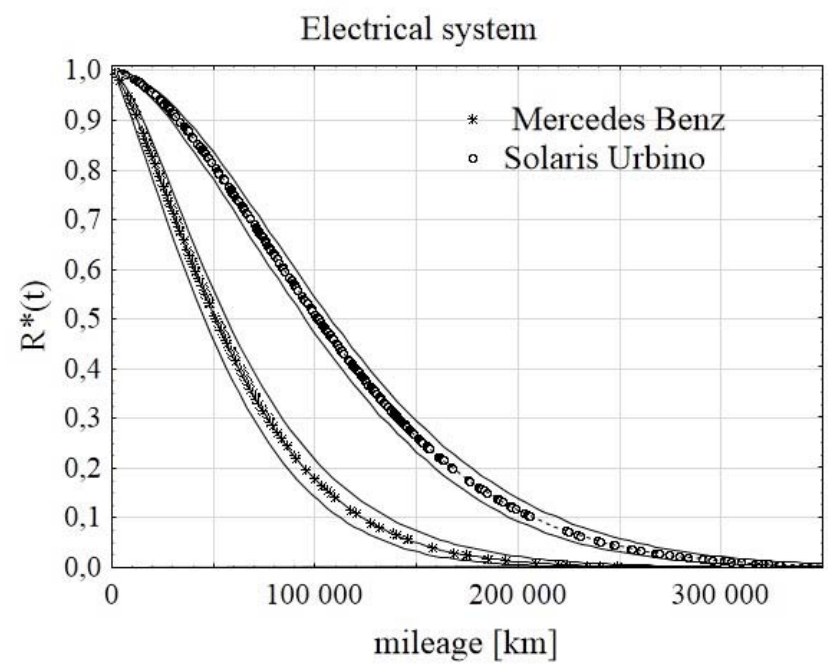

Figure 4. Reliability function diagram of the electrical system of Solaris Urbino and Mercedes Benz buses

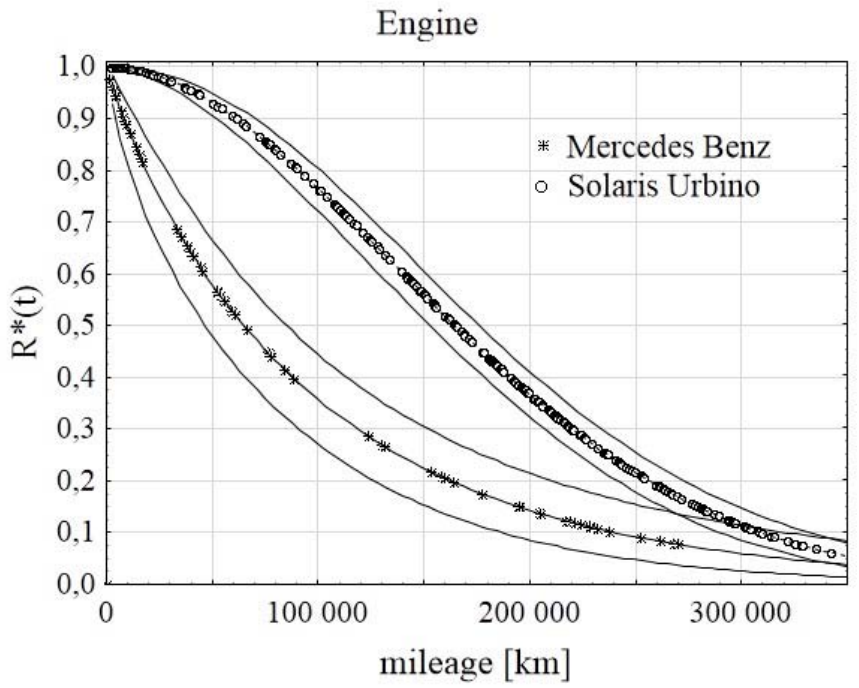

Figure 5. Reliability function diagram of the engine of Solaris Urbino and Mercedes Benz buses

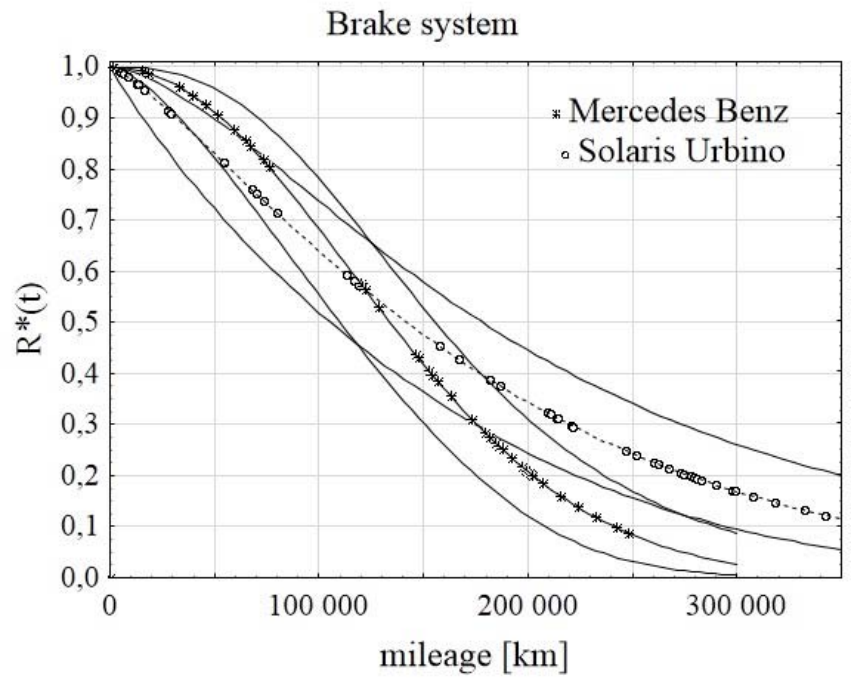

Figure 6. Reliability function diagram of the brake system of Solaris Urbino and Mercedes Benz buses 


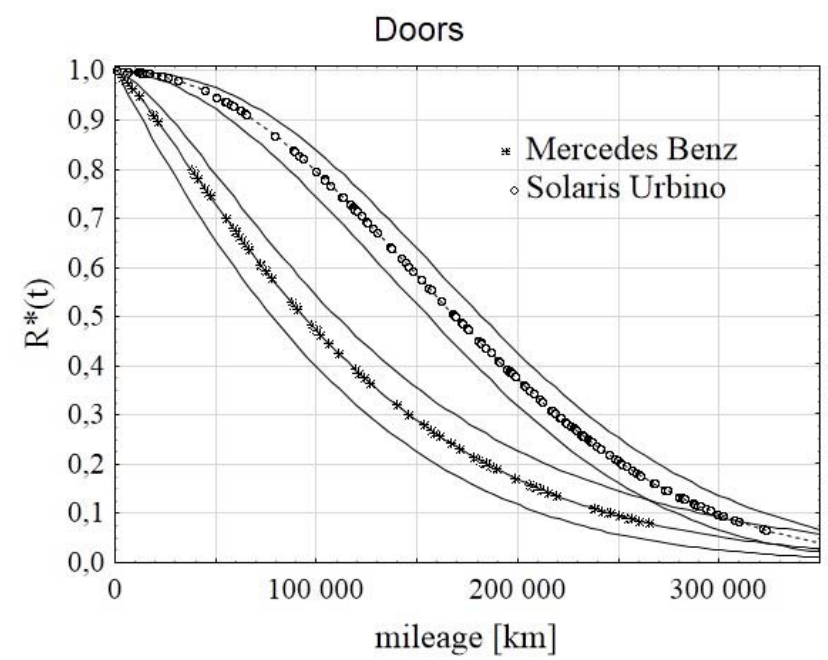

Figure 7. Reliability function diagram of the doors of Solaris Urbino and Mercedes Benz buses

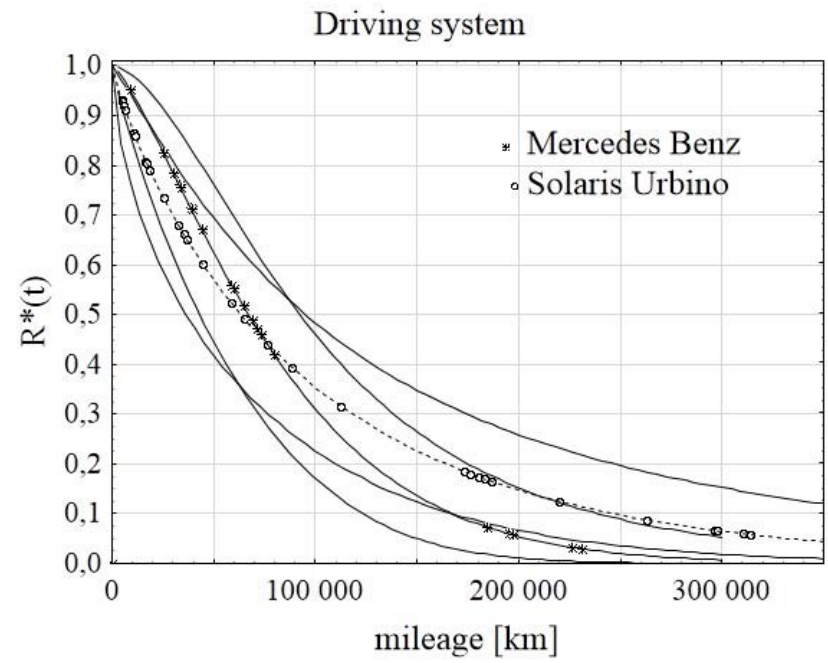

Figure 8. Reliability function diagram of driving system of Solaris Urbino and Mercedes Benz buses

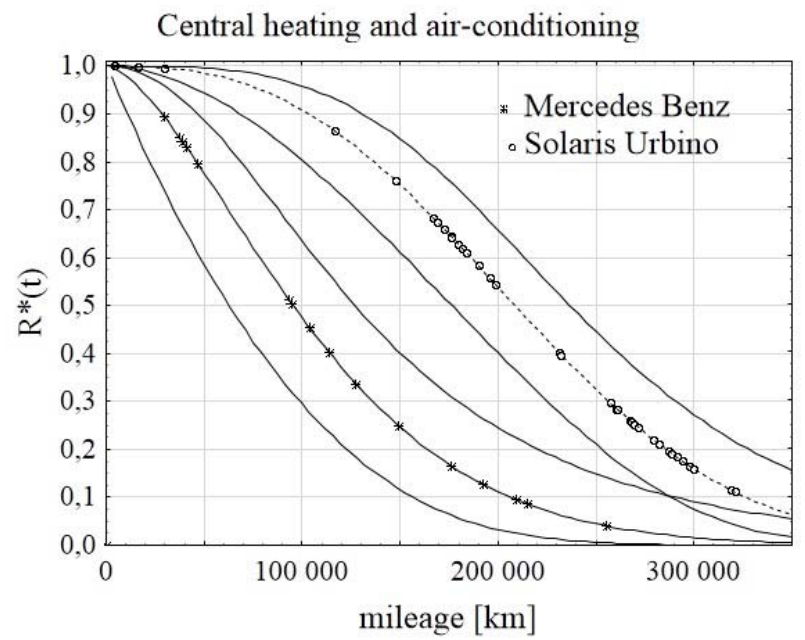

Figure 9. Reliability function diagram of the central heating and air-conditioning system of Solaris Urbino and Mercedes Benz buses 


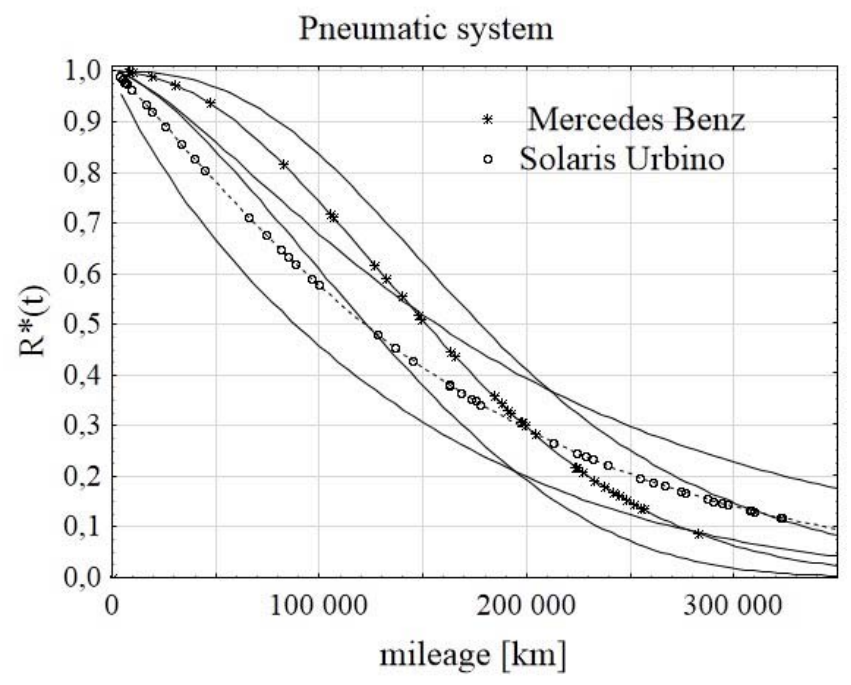

Figure 10. Reliability function diagram of the pneumatic system of Solaris Urbino and Mercedes Benz buses

A reliability analysis of all analyzed bus systems for Solaris and Mercedes buses according in relation to their operating mileage is presented in figure 3. A significant decrease in reliability of Mercedes buses began to appear after 28 thousand $\mathrm{km}\left(\mathrm{R}^{*}(\mathrm{t})=0.8\right)$, and after 100 thousand km reliability is just 0.37 . However for Solaris buses respective level of reliability can be observed in the longer mileage $\mathrm{R}^{*}(\mathrm{t})=0.8$ with more than 63 thousand $\mathrm{km}$, and $\mathrm{R} *(\mathrm{t})=0.37$ is equal 164 thousand $\mathrm{km}$. The graph also presents the line fitted to the data points. The boundary lines of the confidence interval of $95 \%$ are indicated.

Figures $4-10$ present the results of reliability analysis of all studied systems of Mercedes and Solaris buses. In case of the electrical system of Solaris buses the decrease in reliability occurs after the mileage of 51.6 thousand $\mathrm{km}(\mathrm{R} *(\mathrm{t})=0.8)$. The level of $\mathrm{R}^{*}(\mathrm{t})=0.5$ is reached after 101 thousand $\mathrm{km}$ mileage. The level of $\mathrm{R}^{*}(\mathrm{t})=0.8$ states at the mileage of 23 thousand $\mathrm{km}$ for Mercedes buses. In case of Mercedes buses in the first 51 thousand $\mathrm{km}$ mileage the reliability decreases half of the value. Similar tendency is observed in case of the driving system, where reliability $\mathrm{R}^{*}(\mathrm{t})=0.8$ occurs at the mileage of 30 thousand $\mathrm{km}$ and 18 thousand $\mathrm{km}$, respectively, for Mercedes and Solaris buses, and $\mathrm{R}^{*}(\mathrm{t})=0.5$ after the mileage of 65 thousand $\mathrm{km}$ for both types of buses.

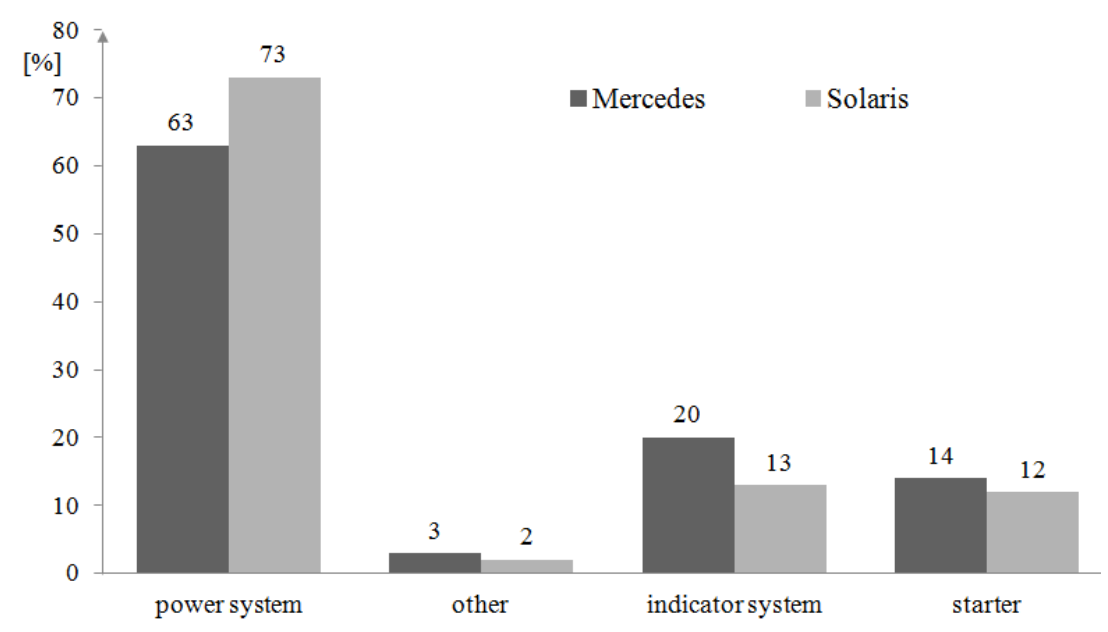

Figure 11. The failures percentage of individual components of the electrical system of Solaris Urbino and Mercedes Benz buses

The reliability analysis of the brake and pneumatic system of both types of buses decreases in the range of vehicle mileage. A slight decrease in reliability of Mercedes buses began to appear between 0-60 thousand $\mathrm{km}$, and after 100 thousand $\mathrm{km}$ the reliability of Solaris buses is higher than in Mercedes.

The reliability results of the door and central heating and air-conditioning system of the Solaris buses show it's significant advantage over Mercedes buses. In case of the central heating and air-conditioning 
system the reliability level $\mathrm{R}^{*}(\mathrm{t})=0.8$ was observed at 47 thousand $\mathrm{km}$ mileage for Mercedes buses and at 136 thousand $\mathrm{km}$ mileage for Solaris buses.

A similar situation appears in case of the door system, where reliability decreases to the value of $\mathrm{R}^{*}(\mathrm{t})=0.8$ after 38 thousand $\mathrm{km}$ and 95 thousand $\mathrm{km}$ for Mercedes and Solaris buses, respectively, and to the level of $\mathrm{R}^{*}(\mathrm{t})=0.5$, after 91 thousand $\mathrm{km}$ and after 169 thousand $\mathrm{km}$.

Figure 11 presents the failure percentage of the electrical system, where the number of failures is the highest from all of the analyzed systems. Failure of power system was responsible for about $70 \%$ of all failures, and indicator system just $20 \%$ and $13 \%$ for Mercedes and Solaris buses respectively. Other failures (alternator, starter and battery) constitute about $15 \%$ of all electrical system failures.

\section{Conclusion}

The article presents a reliability comparison of city transport buses on the example of Solaris Urbino 12 and Mercedes-Benz 628 Conecto LF at Municipal Transport Company in Lublin. The analysis covered damages of the selected construction systems. This analysis is used to better organized the operating system at Municipal Transport Company, so that the number of failures could be minimized.

Damages were recorded in the range of specific vehicle mileage. Each vehicle travelled on average 350 thousand $\mathrm{km}$ in the analyzed period (54 months of observation).

It can be said that Solaris buses stands out higher failures' mileage and higher total reliability in comparison to the Mercedes buses. Moreover, it has been shown, that the reliability of the various structural systems differs and depends on the brand of the bus. In case of the two analyzed brands the most unreliable systems were electrical system, engine and door mechanisms. However, the highest risk of failure was found in the case of driving system and central heating and air-conditioning system.

\section{References}

1. Aksezer, C. S. (2011) Failure analysis and warranty modelling of used cars. Engineering Failure Analysis, 18, 1520-1526. DOI: 10.1016/j.engfailanal.2011.05.009

2. Attardi, L., Guida, M., Pulcini, G. (2005) A mixed-Weibull regression model for the analysis of automotive warranty data. Reliability Engineering and System Safety, 87, 265-273. DOI: 10.1016/j.ress.2004.05.003

3. Bocchetti, D., Giorgio M., Guida M., Pulcini G. (2009) A competing risk model for the reliability of cylinder liners in marine Diesel engines. Reliability Engineering and System Safety, 94, 1299-1307. DOI: $10.1016 /$ j.ress.2009.01.010

4. Chukova, S, Arnold, R, Wang, DQ. (2004) Warranty analysis: an approach to modelling imperfect repairs. International Journal of Production Economy, 89(1), 57-68. DOI: 10.1016/S09255273(03)00200-7

5. Gołąbek, A. (1993) Niezawodność autobusów. Wrocław: Wydawnictwo Politechniki Wrocławskiej

6. Gong, Z. (2006) Estimation of mixed Weibull distribution parameters using the SCEM-UA algorithm: Application and comparison with MLE in automotive reliability analysis. Reliability Engineering and System Safety, 91, 915-922. DOI: 10.1016/j.ress.2005.09.007

7. Grabski, F., Jaźwiński, J. (2009) Funkcje o losowych argumentach w zagadnieniach niezawodności, bezpieczeństwa i logistyki. Warszawa: WKiE

8. Grądzki, R., Lindstedt, P. (2015) Method of assessment of technical object aptitude in environment of exploitation and service conditions. Eksploatacja i Niezawodnosc - Maintenance and Reliability, vol. 17, no. 1, 54-63. DOI: dx.doi.org/10.17531/ein

9. Kaplan, E.L., Meier, P. (1958) Nonparametric estimation from incomplete observations. Journal of American Statistical Assocation, 53, 457-481. DOI: 10.1080/01621459.1958.10501452

10. Kleynera, A., Sandborn, P. (2005) A warranty forecasting model based on piecewise statistical distributions and stochastic simulation. Reliability Engineering and System Safety, 88, 207-214. DOI: 10.1016/j.ress.2004.07.016

11. Majeske, K. D. (2007) A non-homogeneous Poisson process predictive model for automobile warranty claims. Reliability Engineering and System Safety, 92, 243-251. DOI: 10.1016/j.ress.2005.12.004

12. Matuszak, Z. (2010) Estimation of the availability of the power-propulsion and technological system of a fishing vessel at selected operational model. Eksploatacja i Niezawodnosc-Maintenance and Reliability, vol. 45, no. 1, 49-58. DOI: dx.doi.org/10.17531/ein 
13. Murthy, D.N.P., Djamaludin, I. (2002) New product warranty: A literature review. International Journal of Production Economics, 79, 231-260. DOI: 10.1016/S0925-5273(02)00153-6

14. Naikan, VNA, Kapur, S. (2006) Reliability modelling and analysis of automobile engine oil. Journal of Automobile Engineering, 220(2), 187-94. DOI: 10.1243/095440706X72637

15. Pecht, M. (2006) Establishing a relationship between warranty and reliability. Electronics Packaging Manufacturing, IEEE Transactions, 29(3), 184-90. DOI: 10.1109/TEPM.2006.881765

16. Rymarz, J., Niewczas, A., Pieniak, D. (2013) Reliability analysis of the selected brands of city buses at municipal transport company, Journal of KONBiN 2(26), 111-122. DOI: 10.2478/jok-2013-0087.

17. Shafiee, M., Chukova, S. (2013) Maintenance models in warranty: A literature review. European Journal of Operational Research, 229, 561-572. DOI: 10.1016/j.ejor.2013.01.017

18. Vališ, D., Žák, L., Pokora, O. (2015) Contribution to system failure occurrence prediction and to system remaining useful life estimation based on oil field data. Proceedings of the Institution of Mechanical Engineers, Part O: Journal of Risk and Reliability, vol. 229, no. 1, 36-45. DOI: $10.1177 / 1748006 \times 14547789$ 